\title{
COMEMORAÇÃO DO CENTENÁRIO DA ELEIÇÃO E POSSE DO PRESIDENTE AFFONSO PENNA
}

TRIBUTE OF CENTENARY FOR OCCASION OF TIIE OWNERSHIP OF THE PRESIDENT AFFONSO PENNA

(Depoimento do bisneto Affonso Augusto Moreira Penna em solenidade realizada em 07 de outubro de 2006, no Instituto Histórico e Geográfico de Minas Gerais, Belo Horizonte)

\section{Sumário}

Este evento foi publicado nesta Revista por solicitação da familia do conselheiro e presidente Affonso Penna, cujo bisneto. Affonso Augusto Moreira Penna, esteve em visita na redação da Revista da Faculdade de Direito da Universidade de São Paulo, em novembro de 2006. Ressaltase que o Senhor Presidente da Comissão de Publicação, ministro do Supremo Tribunal Federal, Professor Titular do Departamento de Direito do Estado, ENRIQUE RICARDO LEWANDOWSKI, em nome dos demais membros, acatou a sua publicação, em dezembro do ano letivo. Salienta-se, por último, que o presidente Affonso Penna foi aluno desta Academia de Direito, tendo colado grau como bacharel no dia 28 de outubro de 1870. Turma n. 39/1870.

O Editor.

Em nome da família do conselheiro e presidente Affonso Penna, expresso, mais uma vez, sumamente honrado e comovido, nossos agradecimentos pelas sucessivas e significativas homenagens da boa gente de Minas Gerais, neste ano em que se comemora o centenário da eleição e posse do ilustre santa-barbarense, primeiro mineiro a ocupar a suprema magistratura da nação brasileira.

Sendo engenheiro, perdoem-me as falhas da oratória, qualidade abundante nos que me precederam.

Em 11 de agosto, Dia do Advogado, na vetusta casa de Affonso Penna Faculdade de Direito UFMG -. em meu depoimento, denominei de Quadra Virtuosa os vértices - Instrução, Justiça, Trabalho Incansável e Saber Múltiplo - que compuseram a trajetória da vida pública do presidente Affonso Penna.

Os amigos depoentes que hoje me antecederam prestaram valiosas informações históricas sobre o conselheiro.

Como estamos num eminente Instituto Histórico e Geográfico, repassolhes aspectos da Geografia na história do presidente.

A seguir, cito alguns, dentre os diversos locais que receberam a presença ou ações enficazes do primeiro presidente mineiro. 
Após sua eleição e antes da posse, Affonso Penna encetou memorável e longa viagem a vários Estados e Municípios das várias regiões do País. O objetivo principal era encontrar e ouvir dirigentes e líderes políticos estaduais e municipais, bem como a população dos mais afastados rincões do País, sobre os problemas de cada um e discutir as alternativas de soluções. ('ito apenas um conhecido brasileiro que the prestou informações valiosas sobre os problemas do sertanejo nordestino, o famoso Padre Cícero. Mais tarde, suas ações positivas e eficazes de governo demonstraram quão útil foi sua viagem.

O Dr. Álvaro da Silveira, que o acompanhou durante a viagem. escreveu no seu livro - "Viagem pelo Brasil Notas e impressões colhidas na viagem do Sr. Dr. Affonso Penna 02/05/1906 a 24/08/1906:

Total da viagem: $16.112 \mathrm{~km}$ por águas oceânicas e fluviais, $5.317 \mathrm{~km}$ por estradas de ferro. Capitais visitadas: Rio de Janeiro. São Paulo. Salvador, Recife. Belém, Porto Alegre, Fortaleza, São Luiz, Curitiba, Manaus, Maceió, João Pessoa. Florianópolis, Teresina, Belo Horizonte, Aracaju, Natal e Vitória"

Entretanto. o ministro Ciro Gomes desconhece a história do primeiro mineiro a exercer a Presidência da República. Conforme informou o jornal "Estado de Minas" em 03/06/2004. na cerimônia de encerramento do lançamento da (âmara Política de Integração Nacional e Desenvolvimento Regional, o ministro Ciro Gomes elogiou o presidente Lula, dizendo "O único presidente, além de Lula. que conheceu o Brasil tão bem e com tanta sensibilidade, Foi Juscelino Kubitschek." Ainda bem que temos. na Presidência do Instituto Histórico e Geográfico de Minas Gerais, um brasileiro de escol e proficuo escritor - o Dr. Marco Aurélio Baggio - que em depoimento recente, afirmou:

\section{"o presidente Affonso Penna foi o grande e verdadeiro precursor do presidente Juscelino Kubitschek"}

Assim, antes da posse, o presidente Affonso Penna percorria as diversas regiões geográficas do nosso País, ouvindo os problemas e anseios do povo. bem como discutindo as soluções com os dirigentes estaduais e municipais.

Durante seu curto Governo presidencial, ou seja, dois anos, seis meses e vinte e nove dias, porém proficuo nas ações e realizações, jamais poupou sua saúde. Deslocava-se, algumas vezes adoentado, para discutir, "in loco" obras em fase de projeto, e mais tarde comparecia às respectivas inaugurações.

Menciono apenas alguns, dentre inúmeros exemplos de sua presença nas inaugurações: 
- em 1908, trecho com quatro estações na Estrada de Ferro Noroeste do Brasil;

em abril de 1909, $103 \mathrm{~km}$ de linha férrea entre União da Vitória c Taquaral Liso (hoje Caçador, Santa Catarina), onde há a antiga Estação Presidente Penna;

antiga sede do Tribunal de Justiça Federal no Rio de Janeiro;

Instituto Oswaldo Cruz/Manguinhos, estabelecimento modelar no ramo da infectologia, no Rio de Janeiro.

Vários prédios e locais públicos reverenciam a memória e o nome do presidente Affonso Penna. Dentre eles:

- escolas públicas em diversos municípios;

- avenidas. ruas e praças, em várias cidades do País, sendo magnífico exemplo a Avenida Affonso Penna, em Belo Horizonte;

- estação do metrô do Rio de Janeiro:

- Aeroporto Affonso Penna, em Curitiba. Segundo me informou o governador do Paraná, Nei Braga. foi a concretização de uma homenagem, pleiteada pela colônia plonesa, que se radicou naquele Estado:

museu da imigração japonesa na cidade de São Paulo, onde está seu retrato na primeira sala de visitação.

Recentemente, visitei o centro histórico da cidade de São Paulo, onde se encontra o Museu Padre José de Anchieta cujo ilustre nome foi dado, por seus pais, ao nosso amigo, o grande mecenas santa-barbarense e brilhante advogado Dr. José de Anchieta da Silva, eminente presidente do Instituto dos Advogados de Minas Gerais. Ao subir a escada interna do Restaurante e Café Girondino, estabelecido na era colonial, deparei-me com a foto, tirada em 1908, mostrando um arco do triunfo, adornado de flores, especialmente montado para recepcionar o presidente Affonso Penna durante sua visita à Capital paulista.

Para não nos restringirmos à geografia do Brasil, relato-lhes um fato que abordei, neste ano. em depoimento à Câmara Municipal de Santa Bárbara. Naquela oportunidade. o dinâmico prefeito de Santa Bárbara e presidente da Associação das Cidades Históricas de Minas Gerais - Antônio Eduardo Martins - sancionou o DecretoLei que criou o Memorial Affonso Penna. a ser implantado na casa em que o conselheiro morou. 
$\mathrm{Na}$ mesma ocasião, mostrei, em vídeo, aos santa-barbarenses, que a história do seu ilustre conterrâneo estava documentada até mesmo em país antípoda do nosso - a República Popular da China. A brilhante jornalista das Organizações Globo, Sonia Bridi, junto ao fotógrafo Paulo Zero, em reportagem sobre o Arquivo Imperial da China, localizado na Cidade Proibida em Pequim, mostrou um documento cuidadosamente guardado. Nele, o presidente Affonso Penna, em oficio manuscrito na língua francesa, redigido em 1906, informava ao Imperador da China haver assumido a suprema magistratura da Nação brasileira e formulava votos para o estreitamento das relações diplomáticas, comerciais e culturais entre os dois países.

A atividade lebril e sua baixa estatura física, registradas pelos cronistas e caricaturistas daquela época. Ihe valeram a alcunha de "Presidente Tico-Tico" Embora haja outras versões para a causa de sua morte prematura em 14 de junho de 1909, creio que a verdade está com Rodrigo Elias, doutorando de Pós-Graduação em História Social da UFRJ, que disse em artigo na revista "Nossa História", de abril de 2006: "Affonso Penna tornou-se o primeiro presidente a morrer no Palácio do Catete e o único a expirar por excesso de trabalho."

Em seu leito de morte, no Palácio do Catete, na antiga Capital federal, Affonso Penna murmurou, no ouvido do médico Dr. Miguel Couto, a síntese dos valores maiores de sua virtuosa vida:

\footnotetext{
"Deus, Pátria, Família e Liberdade"

Viva Minas Gerais! Viva o Brasil!
}

Arcadas, novembro de 2006. 


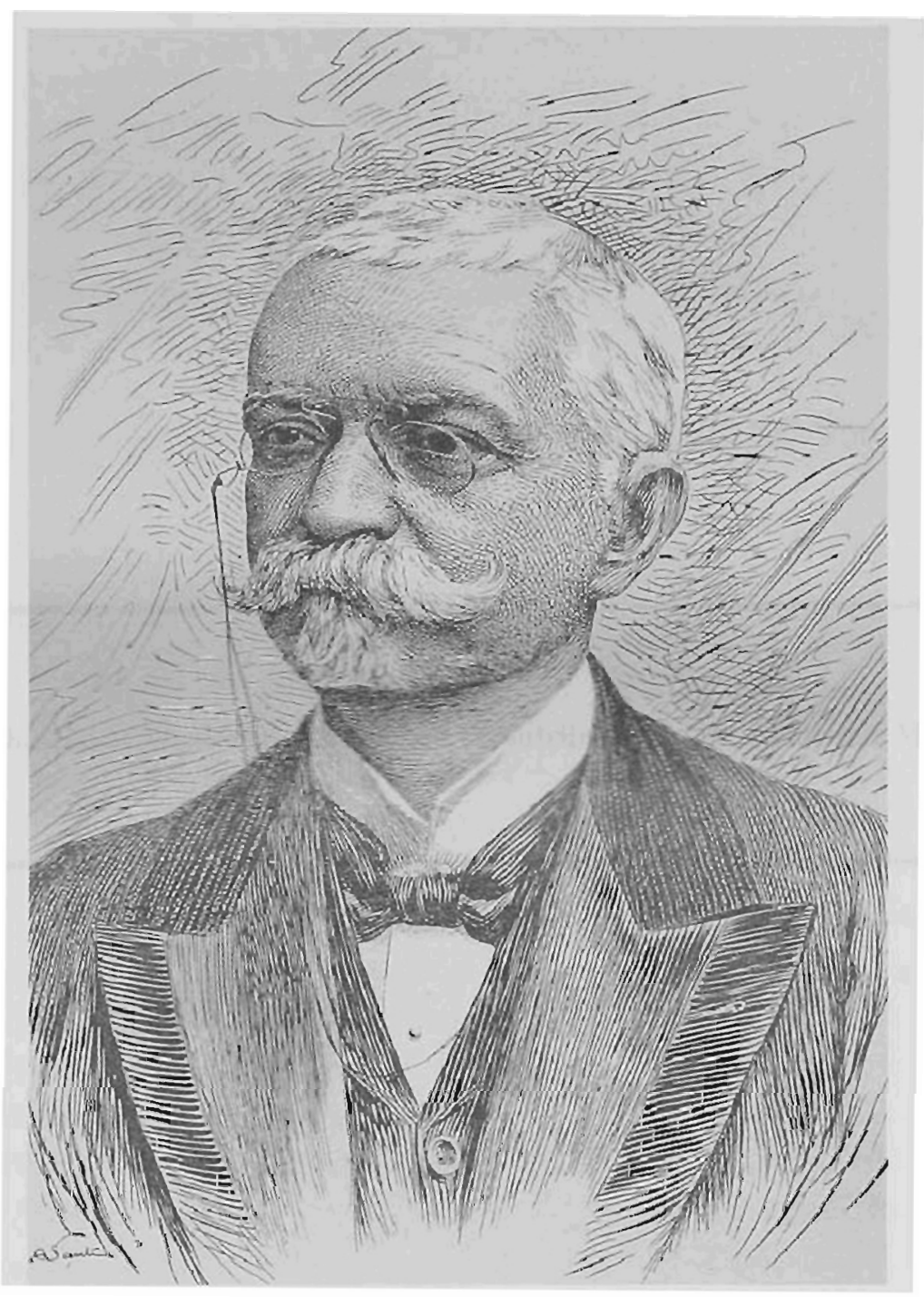

Presidente Affonso Penna 